\title{
Bilateral exudative retinal detachment in a patient with end-stage renal disease - a case report
}

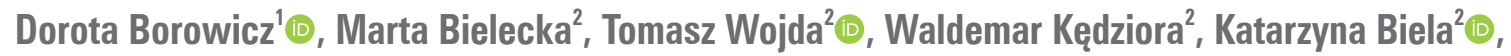 \\ Monika Szyport' ${ }^{2}$ Katarzyna Nowomiejska' ${ }^{1}$, Robert Rejdak ${ }^{1}(\mathbb{0}$ \\ 'Department of General Ophthalmology, Medical University in Lublin, Poland \\ ${ }^{2}$ Department of Ophthalmology, Independent Public Provincial Hospital in Zamość, Poland
}

\begin{abstract}
End-stage renal disease (ESRD) is one of the most severe chronic kidney diseases occurring with a frequency of $0.1 \%$ in the general population. Patients with ESRD are more at risk of ocular complications, therefore cooperation between a nephrologist and an ophthalmologist is recommended. The most common complaints associated with the eye include the conjunctival chemosis, keratopathy, macular edema, optic neuropathy, elevated intraocular pressure and exudative retinal detachment.

In this article, a case report of bilateral exudative retinal detachment in patients with the end-stage renal disease is presented.
\end{abstract}

KEY WORDS: end-stage renal disease; exudative retinal detachment

Ophthalmol J 2019; Vol. 4, 22-27

\section{INTRODUCTION}

End-stage renal disease (ESRD) is the most severe among chronic kidney diseases requiring treatment with dialysis or kidney transplantation. The prevalence of ESRD in the general population is $0.1 \%[1,2]$. In 1836, Richard Wright first described the relationship between kidney disease and blindness [3]. The period of organogenesis for the eyes and kidneys covers the period from the fourth to the sixth week of pregnancy. Disorders in embryogenesis during this period may cause anatomical anomalies and functionalities of both organs [4]. Some inborn renal disorders can lead to ESRD. Patients with end-stage renal disease are more at risk of eye complications. The most common complaints associated with eye include conjunctivitis, keratopathy, macular edema, ischemic optic neuropathy, elevated intraocular pressure, retinal detachment and retinal hemorrhage [5].
In this article, we present a case report of exudative retinal detachment in a patient with end-stage renal disease.

\section{CASE PRESENTATION}

A 31-year-old female reported to the Nephrology Department of Hospital in Zamość due to end-stage renal disease caused by glomerulonephritis. Her medical history informed that she had been treated for chronic glomerulonephritis for 9 years. Moreover, hypertension and diabetes type 2 was diagnosed, she had also had a NSTEMI infarction and caesarean section due to preeclampsia in the past. The laboratory results were as follows: creatinine $10.6 \mathrm{mg} / \mathrm{dL}$, urea $165 \mathrm{mg} / \mathrm{dL}$, erythrocytes $2.61 \mathrm{million} / \mathrm{uL}$, hemoglobin $7.98 \mathrm{~g} / \mathrm{dL}$, electrolytes were $\mathrm{Na} 140.6 \mathrm{mmol} / \mathrm{L}$ and $\mathrm{K} 5.30 \mathrm{mmol} / \mathrm{L}$, D-dimers $15371 \mathrm{ng} / \mathrm{mL}, 4.8$ mg\% glycated hemo- 


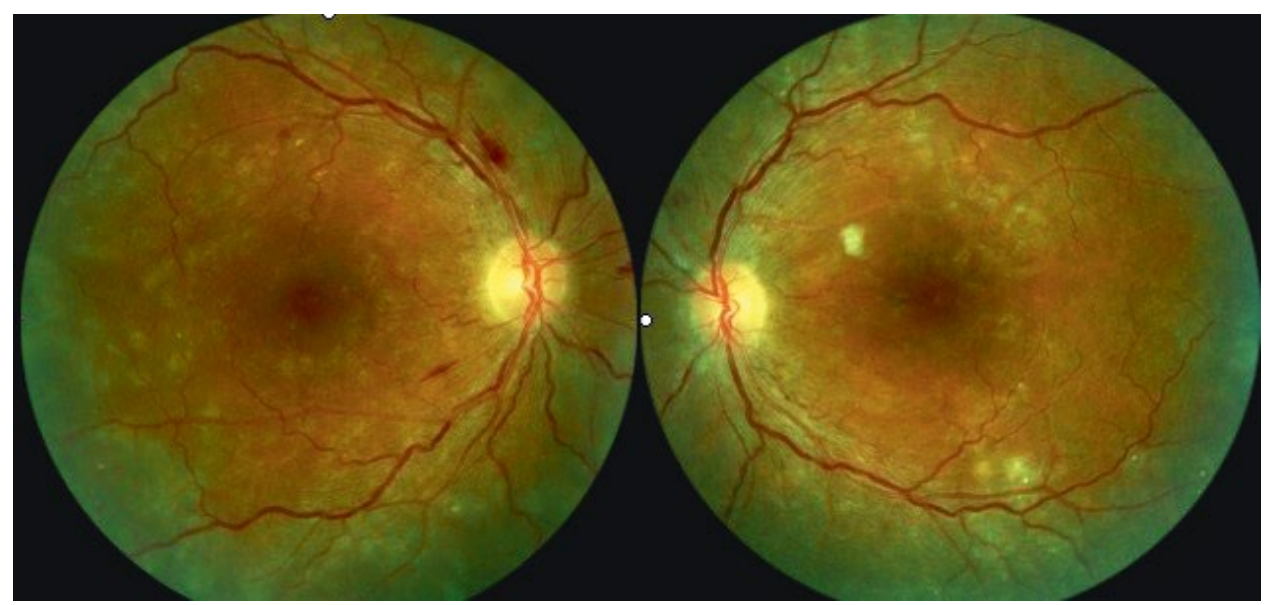

FIGURE 1. The fundus examination of both eyes showing hyperemic discs and multiple pockets of subretinal fluid in the posterior pole of both eyes

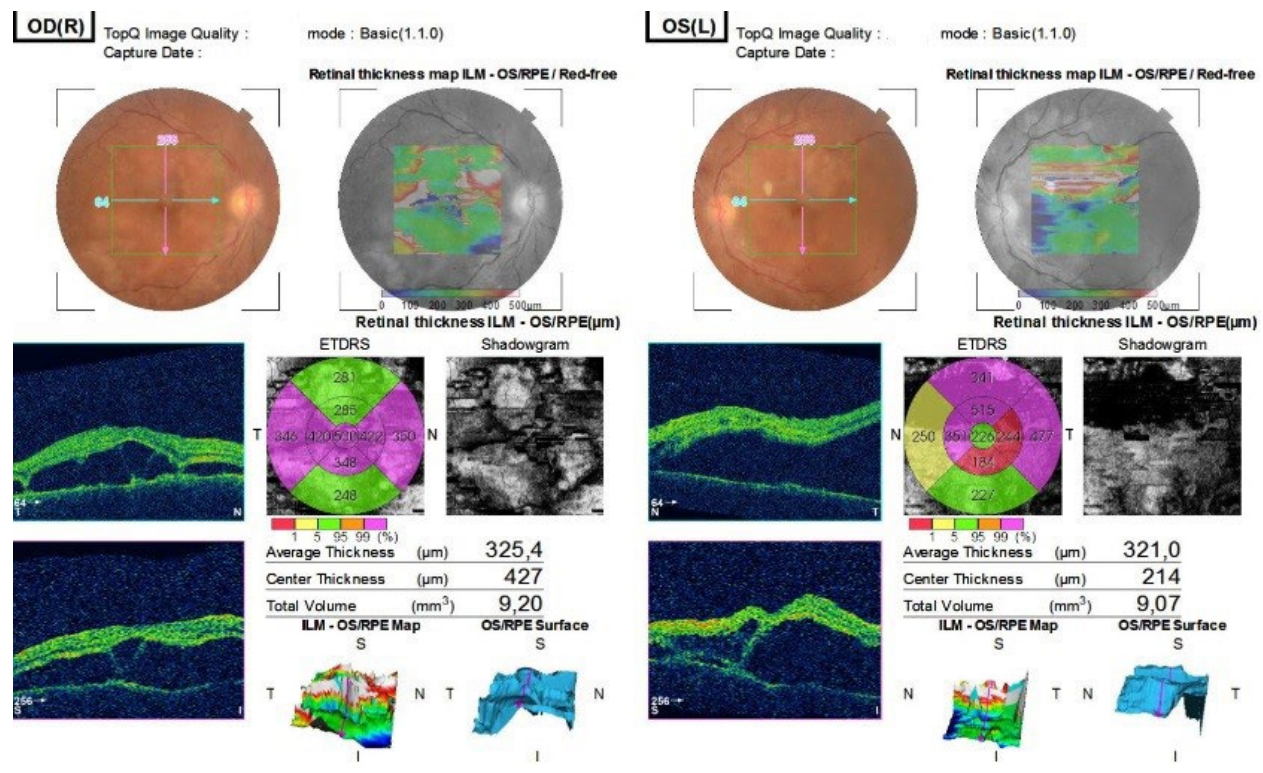

FIGURE 2. OCT scans showing fluid under the sensory retina in the macular region of both eyes

globin and diurnal urine collection showed proteinuria. Her blood pressure was 180/100 mm Hg. The patient was selected for dialysis. The patient showed hypoproteinemia in the blood $(5.96 \mathrm{~g} / \mathrm{dl})$ and hypoalbumienemia $(2.90 \mathrm{~g} / \mathrm{dl})$ after 3 dialyses. The patient was consulted ophthalmologically due to a sudden bilateral deterioration of vision. The best-corrected visual acuity (BCVA) was 0.075 in the right eye and "hand motions" the left eye. The intraocular pressure was $10 \mathrm{~mm} \mathrm{Hg}$ in both eyes. Ophthalmological examination showed normal anterior segment, normal optic disc, retinal detachment with macular involvement, retinal hemorrhages and hard and cotton ball exudates, winding venous vessels and arteriovenous crossings (Fig. 1). The examination optical coherence tomography (OCT) and B scan of ultrasound examination confirmed the presence of retinal detachment (Fig. 2, 3). The patient was advised to continue dialysis and received prednisone $30 \mathrm{mg}$ orally. The patient was disqualified from fluorescein angiography due to a general health condition. Thus, OCT-angio examination was performed and showed abnormal microvasculature of the retina (Fig. 4). The patient underwent 13 dialyses during a 17-days of hospital follow-up. The BCVA was 0.5 in the right and 0.3 in the left eye on the day of discharge. The intraocular pressure was $7 \mathrm{~mm} \mathrm{Hg}$ in the right and $5 \mathrm{~mm} \mathrm{Hg}$ 


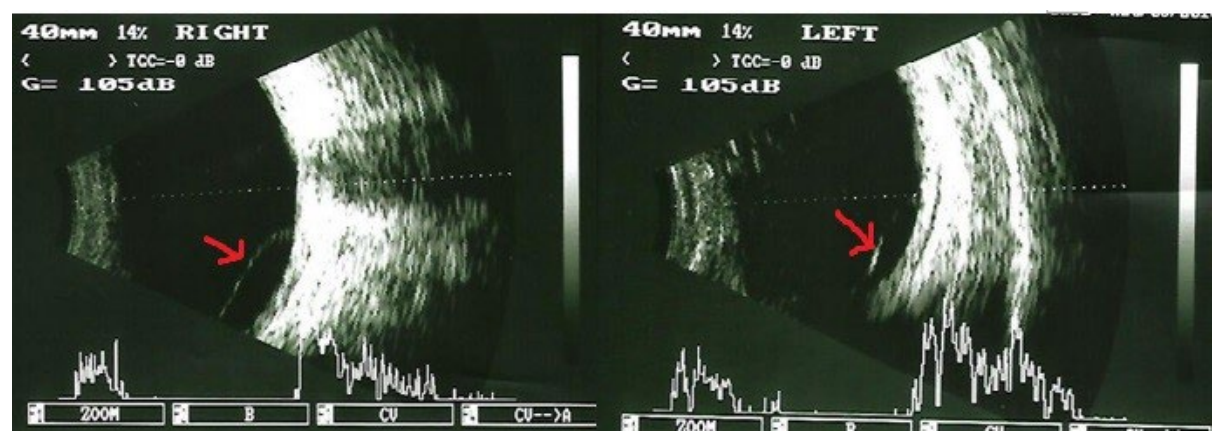

FIGURE 3. B-scan of ultrasound examination showing the retinal detachment in both eyes

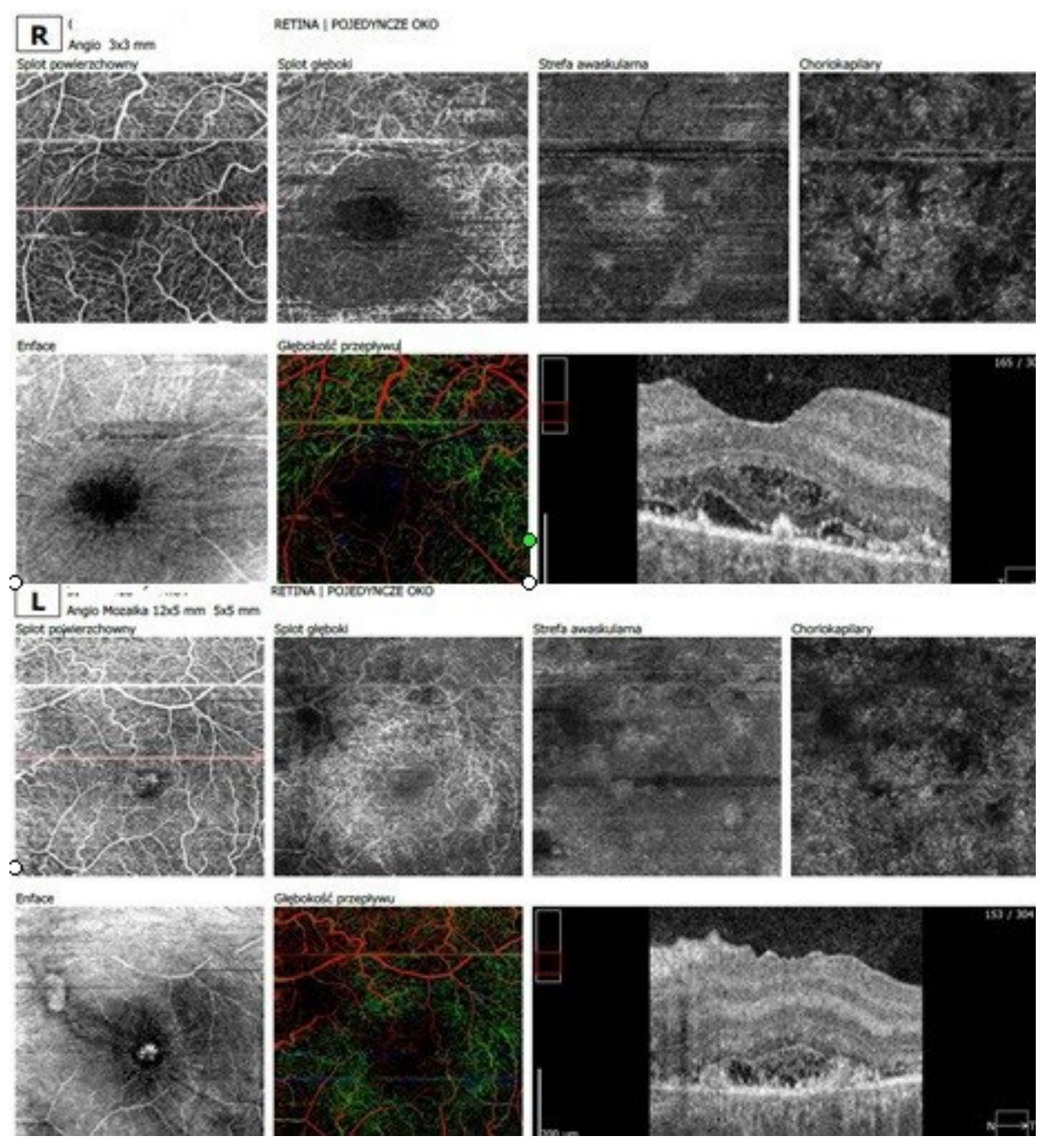

FIGURE 4. OCT-A scans showing abnormal retinal microvasculature of both eyes

in the left eye. The fundus examination of both eyes showed positive Gunn symptom, haemorrhages and retinal vascular tortuosity, retinal detachment in the lower quadrants of the retina. We observed partial resorption of subretinal fluid in the OCT. The patient was discharged on $15 \mathrm{mg}$ prednisone from the hospital. The BCVA was $0.4 \mathrm{cc}$ and $0.4 \mathrm{cc}$ in both eyes after one month. The fundus examination of both eyes showed venous and arteries hardened and winding, positive Gunn symptom, an increase of haemorrhages in the retina and partial resorption of subretinal fluid in lower quadrants (Fig. 5). OCT 


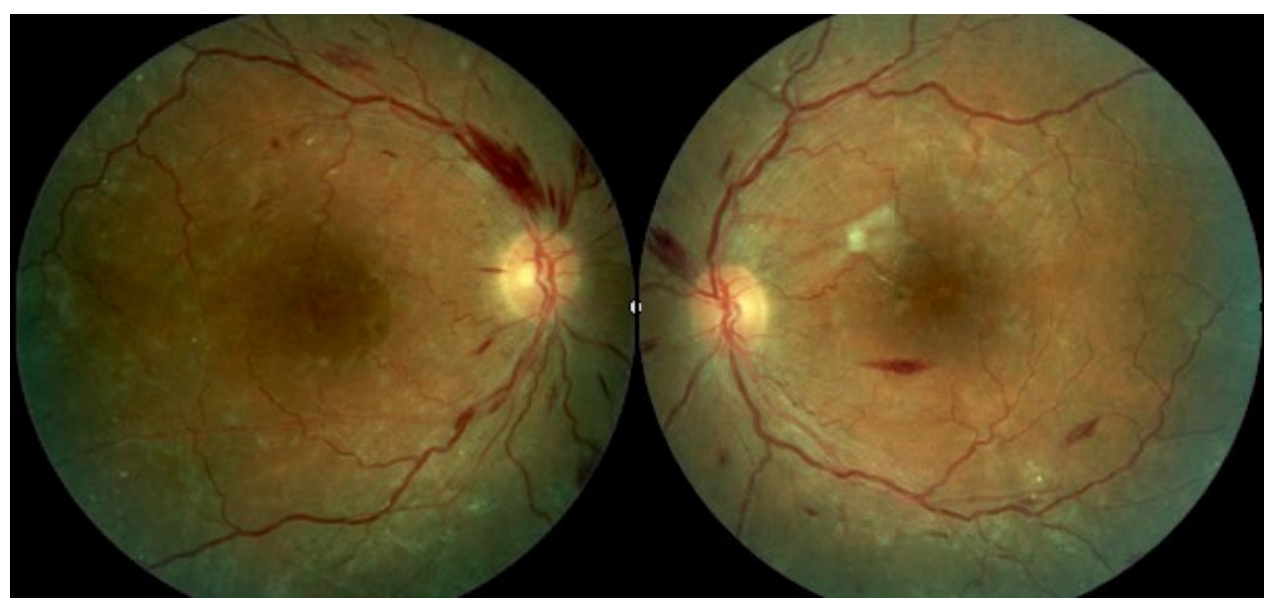

FIGURE 5. The fundus examination after one month showing hyperemic discs, intraretinal hemorrhages, hard and soft exudations, yellowish placoid lesions and narrowed arterial and venous blood vessels of both eyes
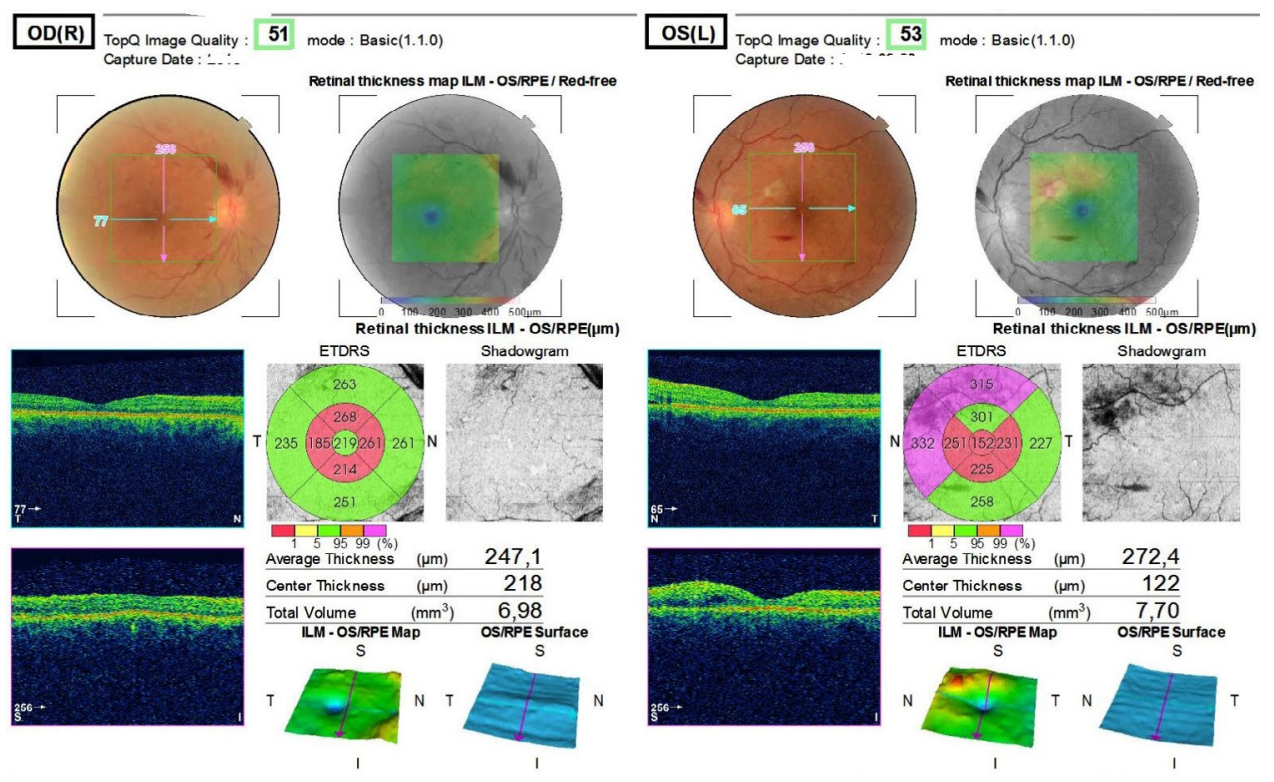

FIGURE 6. OCT scans after one month showing adhesion of the retina in the macular region of both eyes

showed an adhesion of the retina in the macular area (Fig. 6). A slight elevation of neurosensory retina occurred in the lower quadrants of the retina, which was confirmed by B-scan ultrasound (Fig. 7). The patient is still under strict ophthalmological and nephrological control.

\section{DISCUSSION}

End-stage retinal disease (ESRD) is associated with the potential risk of ocular complications, among others exudative retinal detachment (ERD). ERD occurs when the neurosensory retina separates from the retinal pigment epithelium leading to the visual impairment. The cause of the exudate is often not unequivocal, it may be present due to increased permeability and perfusion of the choroidal vessels, disorders of retinal pigment epithelium retention or changes in osmolarity and in a consequence fluid shift between different spaces. The potential causes of ERD should consider idiopathic, vascular, neoplastic, postsurgical, uveitis, systemic inflammatory diseases and infectious diseases [5, 6]. It is important to find the reason of differentiation, whether exudation is caused by primary ocular pathology or secondary in the course of the systemic disease. Ocular causes include intraocular tumours and posterior scleritis [7]. 


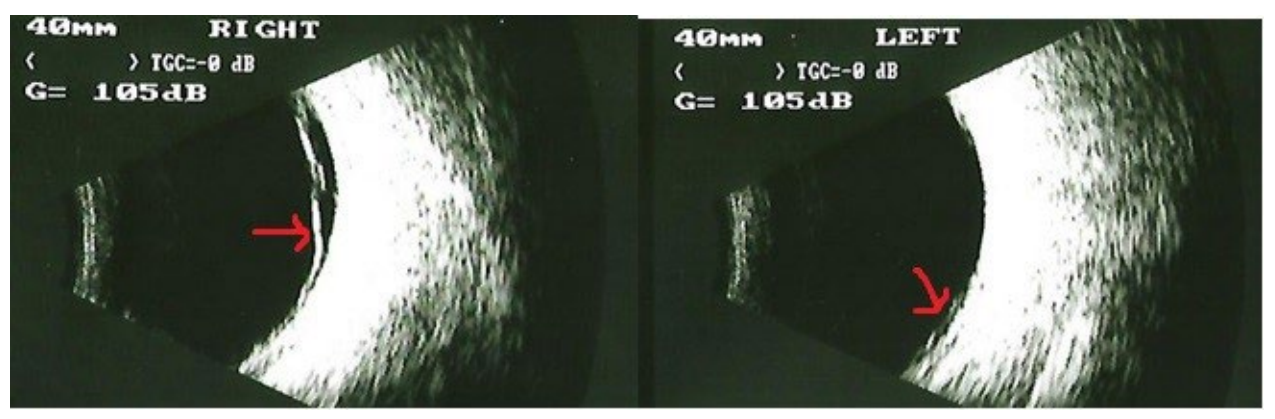

FIGURE 7. B-scan of ultrasound examination after one month showing the retinal detachment in the lower hemisphere of the retina of both eyes

Vogt-Koyanagi-Harada syndrome (VKH) should also be considered in the differential diagnosis of ERD. VKH is systemic inflammation with ophthalmic, neurological and skin lesions caused by an immune response to melanocytic cell antigens [8]. It usually affects young women. Its characteristic feature is a presence of bilateral serous retinal detachment including a macula and an increase degrees of vitreous cells. Zalts et al. described two cases of VKH syndrome development in long-term IgA nephropathy. The authors suggest a similar autoimmune mechanism of both diseases [9].

The literature also includes several reports on the relationship between bilateral exudative retinal detachment secondary to preeclampsia during pregnancy [10].

The bilateral retinal detachment may also be associated with a secondary factor in kidney disease, for example, hypertensive chorioretinopathy [11, 12]. A sudden increase in blood pressure may lead to vasoconstriction and ischemia of the retinal pigment epithelium (Elschnig spots) and consequently allow leakage into the subretinal space contributing to the ERD. Villalba-Pinto et al. reported the case of a 26-year-old man with bilateral massive serous retinal detachment on the background of high blood pressure associated with chronic IV renal failure. The subretinal fluid was resorbed as a result of a dialysis treatment with oral antihypertensive drugs $[13,14]$. In our case, we observed changes characteristic for hypertensive retinopathy as a retina haemorrhages, soft and hard exudates, enlarged and twisted vessels and positive Gunn symptom. Pino et al. demonstrated on animal studies that hypoalbuminaemia causes a decreases osmotic pressure which affects a passage of fluid into the subretinal space [15]. The literature also describes cases of bilateral retinal detachment secondary to hypoalbuminemia
$[16,17]$. Wong et al. presented a description of three cases of exudative retinal detachment because of hypoalbuminemia [18].

\section{CONCLUSION}

In this paper author reported the case of a young woman with bilateral exudative retinal detachment secondary to end-stage renal disease. The cause of ERD is often complex and multifactorial. Patients with ESRD require close cooperation between a nephrologist and an ophthalmologist due to the risk of potential ocular complications.

\section{REFERENCES}

1. Hill NR, Fatoba ST, Oke JL, et al. Global Prevalence of Chronic Kidney Disease - A Systematic Review and Meta-Analysis. PLoS One. 2016; 11(7): e0158765, doi: 10.1371/journal.pone.0158765, indexed in Pubmed: 27383068.

2. Hassanien AA, Al-Shaikh F, Vamos EP, et al. Epidemiology of endstage renal disease in the countries of the Gulf Cooperation Council: a systematic review. JRSM Short Rep. 2012; 3(6): 38, doi: 10.1258/ shorts.2012.011150, indexed in Pubmed: 22768372.

3. Bright R. Tabular view of the morbid appearances in 100 cases connected with albuminous urine. Guy's Hosp Rep. 1836; 1: 380.

4. Bodaghi B, Massamba N, lzzedine $H$, et al. The eye: a window on kidney diseases. Clin Kidney J. 2014; 7(4): 337-338, doi: 10.1093/ ckj/sfu073, indexed in Pubmed: 25852906.

5. Mullaem G, Rosner MH. Ocular problems in the patient with end-stage renal disease. Semin Dial. 2012; 25(4): 403-407, doi: 10.1111/j.1525139X.2012.01098.x, indexed in Pubmed: 22686705.

6 . Anand $R$, Tasman WS. Nonrhegmatogenous retinal detachment. Retina. 2006: 2121-2141, doi: 10.1016/b978-0-323-02598-0.50129-4.

7. Benson WE. Posterior scleritis. Surv Ophthalmol. 1988; 32(5): 297-316, indexed in Pubmed: 3043740.

8. Read RW, Holland GN, Rao NA, et al. Revised diagnostic criteria for Vogt-Koyanagi-Harada disease: report of an international committee on nomenclature. Am J Ophthalmol. 2001; 131(5): 647-652, indexed in Pubmed: 11336942.

9. Zalts R, Hayek T, Baruch $Y$, et al. Vogt-Koyanagi-Harada syndrome associated with renal failure: a case report. J Nephrol. 2006; 19(2): 225-228, indexed in Pubmed: 16736427.

10. Tranos PG, Wickremasinghe SS, Hundal KS, et al. Bilateral serous retinal detachment as a complication of HELLP syndrome. Eye (Lond). 2002; 16(4): 491-492, doi: 10.1038/sj.eye.6700056, indexed in Pubmed: 12101460.

11. Liu DTL, Shields JA, Li CL, et al. Hypertensive choroidopathy in Castleman's disease. Graefes Arch Clin Exp Ophthalmol. 2011; 
249(12): 1901-1903, doi: 10.1007/s00417-011-1721-x, indexed in Pubmed: 21678090.

12. Rao G, Dash S, Kanungo G, et al. Bilateral exudative multifocal retinal detachment: An unusual presentation of accelerated hypertension with obstructive uropathy. Int J Case Reports and Images. 2011; 2(12): 15-18, doi: 10.5348/ijcri-2011-12-74-cr-4.

13. Villalba-Pinto L, Hernández-Ortega MÁ, de Los Mozos FJ, et al. Massive bilateral serous retinal detachment in a case of hypertensive chorioretinopathy. Case Rep Ophthalmol. 2014; 5(2): 190-194, doi: 10.1159/000364942, indexed in Pubmed: 25120474.

14. Rotsos T, Andreanos K, Blounas $S$, et al. Multimodal imaging of hypertensive chorioretinopathy by swept-source optical coherence tomography and optical coherence tomography angiography: Case report. Medicine (Baltimore). 2017; 96(39): e8110, doi: 10.1097/ MD.0000000000008110, indexed in Pubmed: 28953634.
15. Pino RM, Thouron CL, Pino RM, et al. Vascular permeability in the rat eye to endogenous albumin and immunoglobulin $\mathrm{G}(\mathrm{lgG})$ examined by immunohistochemical methods. J Histochem Cytochem. 1983; 31(3): 411-416, doi: 10.1177/31.3.6827079, indexed in Pubmed: 6827079.

16. Venkatramani J, Gottlieb JL, Thomassen TS, et al. Bilateral serous retinal detachment due to protein-losing enteropathy. Arch Ophthalmol. 2004; 122(7): 1067-1070, doi: 10.1001/archopht.122.7.1067, indexed in Pubmed: 15249379 .

17. De Benedetto U, Pastore MR, Battaglia Parodi M, et al. Retinal involvement in nephrotic syndrome secondary to minimal change disease. Eur J Ophthalmol. 2012; 22(5): 843-845, doi: 10.5301/ejo.5000153, indexed in Pubmed: 22562301.

18. Wong MHY, Cheung GCM, Chee SP, et al. Exudative detachment as a masquerader in hypoalbuminaemic patients. Clin Kidney J. 2014; 7(4): 406-410, doi: 10.1093/ckj/sft161, indexed in Pubmed: 25852920. 